Volume 6, No. 4

October - December 2020

www.jrmi.pk

Submitted

November 15, 2020

Accepted

December 10, 2020

Author Information

Ms. Ome Kalsoom Afridi

Department of Biology

Education, Kyungpook

National University, Daegu

41566, Republic of Korea

Dr. Johar Ali

Center for Genomic Sciences

Rehman Medical College

Peshawar, Khyber

Pakhtunkhwa, Pakistan

(Corresponding Author)

Email: johar.ali1@rmi.edu.pk

Citation: Afridi OK, Ali J.

Pakistan specific COVID-19

overview and

recommendations. [Editorial].

J Rehman Med Inst. 2020

Oct-Dec;6(4):1-2.

\title{
Pakistan specific COVID-19 overview and recommendations
}

Ome Kalsoom Afridi, Johar Ali

\section{ABSTRACT}

Soon after its emergence in Wuhan, China in late December, the novel coronavirus (SARS-CoV-2) spread rapidly to the other parts of the world and acquired a pandemic status. Pakistan reported its first case of SARSCoV-2 on February 26, 2020, in Karachi. Since then, a higher prevalence of COVID-19 was reported from almost all major cities of Pakistan. Owing to the high rate of COVID-19, Pakistan enforced a lockdown across the whole country on March 24, 2020. This lockdown controlled the SARS-CoV-2 successfully; however, severe economic losses were observed in the lockdown Standard Operating Procedure (SOP) guidelines. We, therefore, proposed an alternative plan termed as "regulated reverse lockdown" which will help decrease the burden of COVID-19 without having a negative effect on the economy. The present editorial will address the potential flaws in the already imposed lockdown and will propose an alternative plan to make the lockdown more effective in terms of COVID-19 prevalence and economic growth of Pakistan.

The authors declared no conflict of interest. Both authors contributed substantially to the write-up of the editorial, and agreed to be accountable for all aspects of the work.

\section{INTRODUCTION}

\section{Plague and infectious diseases}

The word plague is derived from Doric Greek which means to blow or strike. Being a polysemy, the word plague has been interchangeably used to describe high contractible diseases caused by Yersinia pestis, any epidemic disease with a high mortality rate, or any disease caused by an emerging infectious agent. ${ }^{1}$ Plagues in the form of different outbreaks have drastically affected human populations since time immemorial. ${ }^{2}$ Emerging and re-emerging viral diseases pose a serious threat to the global community. The notable viruses with deleterious global public health concerns include Zika (prevalent in South America), Ebola (common in western Africa), H7N9 (in most parts of Asia and China), and worldwide H1N1 influenza. ${ }^{3}$

\section{Emergence of coronaviruses}

Coronaviruses emerged as novel viruses of the $21 \mathrm{st}$ century with varying symptoms ranging from mild flu to severe respiratory associated complications. Coronaviruses infect different hosts such as bats, snakes, birds, mice, wild animals, and humans. ${ }^{4}$ In late 2002, Severe Acute Respiratory Syndrome (SARS) Coronavirus (SARS-CoV) emerged in
Guangdong, China. SARS-CoV infected 8098 humans across the globe with a total of 774 deaths. Following SARS-CoV infections, another SARS virus named the Middle East Respiratory Syndrome (MERS) emerged in Saudi Arabia in 2012. MERSCoV caused 2494 infections with 858 deaths. ${ }^{3}$ In late 2019, another coronavirus emerged in Wuhan China with usual symptoms of pneumonia. This virus was named SARS-CoV-2 and COVID-19 terminology was used to designate infected cases. Soon after its emergence in China, SARS-CoV-2 transmitted rapidly to various parts of the world including Pakistan, and acquired a pandemic status with an alarming prevalence and mortality rate. Owing to high prevalence of COVID-19, various countries imposed nationwide lockdowns. Pakistan reported its first COVID-19 case on February 26, 2020, in Karachi. Following this, several cities across the country reported COVID-19 positive cases and associated deaths. Keeping in view the high prevalence of SARS-CoV-2, Pakistan imposed a countrywide lockdown on March 24, 2020. Although this lockdown helped in lowering the burden of COVID-19 cases, many factors and flaws were observed in lockdown SOPs.

Different nations adopted variable strategies to continue their research work and combat the COVID-19 pandemic effectively. ${ }^{5-8}$ Despite the imposed lockdown, the scientific community of most nations continued their research work to find suitable vaccine candidates for SARS-CoV-2. It is known that universities have been shut down across the globe due to the COVID-19 pandemic Universities closure due to COVID-19 forced the scientists to work from their homes; however, some researchers (those monitoring clinical trials for finding vaccines, and therapies for various emerging infectious diseases including the novel coronavirus) cannot stop going to their laboratories. ${ }^{9}$ Clinical trials warrant continuous looking after and availability of concerned researchers. Laboratories in several countries devised COVID-19 regulatory SOPs to continue their research activities on site. These scientists managed to continue their research activities by adopting various COVID-19 safety guidelines for instance reducing the number of on-site scientists, online meetings, and use of BSL-3 labs for SARSCoV-2 related research activities. ${ }^{10-12}$ 


\section{Critical problems related to lockdown in Pakistan}

Considering the economic situation of Pakistan, we posed the question that whether the COVID-19 pandemic can be used as an opportunity to move forward. It is evident that the lockdown in Pakistan has created severe strain on the vulnerable part of the population. Most lost their total earnings, and some are paying higher than usual to commute to work and even more exposed to the virus than ever and affecting their families as well. The biggest of all is that few stores managed to stay open which has created a flood of people in one area at one time making the exposure to the virus more likely. In summary, we have increased the likelihood of the number of people at one spot at the same time due to the partial lockdown. People are forced to share unmarked taxis and take on low paying jobs. Much to my surprise this can be mostly equated with a shutter down not lockdown rather a lockdown.

\section{Alternative lockdown plan}

Overall, much is being shared about the COVID-19 effect on people, death rates, social and economic effects, environmental effects, and psychological effects. ${ }^{13-15}$ However, keeping in view the economic situation of Pakistan, we propose an alternate standard operating procedure to contain COVID-19 which also needs to be kept dynamic as future progress are made. Knowing all these effects, the following proposed steps can be implemented across Pakistan round the year or at least in between lockdowns:

1. Government need to carry out an aggressive campaign on the use of masks, sanitizers, and other relevant awareness items.

2. Install trash cans, provide masks to the public, and make sanitizers and tissue papers available everywhere. Once these items are in place, strict ban on people throwing trash, sneezing, coughing, spitting in public, etc. can then be implemented.

3. For accountability and check and balance, cameras need to be installed at every corner of the city.

4. Hire a COVID-19 task force or induct volunteers to implement and enforce the new hygiene rules.

5. Educate people about self-hygiene and to identify common routes of COVID-19 transmission.

6. Train students at schools, colleges, and universities to adopt all safety precautions of COVID-19 and help in spreading awareness to those with no access to such information.

7. Train local taxi drivers, those working in the local transportation system, and other service providers to sanitize the space in public use regularly.

8. Avoid handshake and maintain proper distance of 6 feet at all time.

9. Implement extended work hours to reduce public workflow in one location at one time.

\section{CONCLUSION}

We conclude that the current proposed plan needs a second thought instead of immediate rejection and shall be considered as an alternate plan. Furthermore, we do believe that COVID-19 will continue to spread seasonally without a potential vaccine and thus require us to maintain a functional society in the face of this pandemic. This editorial in no way claims to eradicate or control SARS-CoV-2, but to provide a viable and logical first response to the pandemic

\section{REFERENCES}

1. Huremović D. Brief History of Pandemics (Pandemics Throughout History) Psychiatry of Pandemics. 2019 May 16:735. Available from: https://www.ncbi.nlm.nih.gov/pmc/articles /PMC7123574/pdf/978-3-030-153465_Chapter_2.pdf.

2. Benedictow OJ. The Black Death: the greatest catastrophe ever. History Today. 2005 Mar;55(3):42-9. Available from: https://www.historytoday.com/archive/blac k-death-greatest-catastrophe-ever.

3. Guo D. Old weapon for new enemy: drug repurposing for treatment of newly emerging viral diseases. Virol Sin. 2020 Jun;35(3):253-55.

4. Yang Y, Peng F, Wang R, Guan K, Jiang T, $\mathrm{Xu}$ G, et al. The deadly coronaviruses: The 2003 SARS pandemic and the 2020 novel coronavirus epidemic in China, J Autoimmun. 2020 May;109:102434.

5. M. Hirschey M. Lab life-rebuild it better after coronavirus lockdowns ease. Nature. 2020 Jun;582(7811):184.
6. Omary MB, Eswaraka J, Kimball SD, Moghe PV, Panettieri RA, Scotto KW. The COVID-19 pandemic and research shutdown: staying safe and productive. J Clin Invest. 2020 Jun 1;130(6):2745-8.

7. Saberi P. Research in the time of coronavirus: continuing ongoing studies in the midst of the COVID-19 pandemic. AIDS Behav. 2020 Aug;24(8):2232-5.

8. Subbaraman N. Return to the lab: scientists face shiftwork, masks and distancing as coronavirus lockdowns ease. Nature. 2020 Jun;582(7810):15-6.

9. Krogan N, Vousden K, Doudna J, Schulman BA, Gringas A-C, Dikic I. Science in the wake of the pandemic: how will Covid-19 change the way we do research? Molecular Cell. 2020 July 2; 79:9-10. Available from: https://www.cell.com/molecularcell/pdf/S1097-2765(20)30426-3.pdf.

10. Gewin V. Safely conducting essential research in the face of COVID-19. Nature. 2020 Apr;580(7804):549-50.
11. Viglione G. A year without conferences? How the coronavirus pandemic could change research. Nature. 2020 Mar;579(7799):327-328.

12. Donthu N, Gustafsson A. Effects of COVID-19 on business and research. J Bus Res. 2020 Sep;117:284-9.

13. Atalan A. Is the lockdown important to prevent the COVID-19 pandemic? Effects on psychology, environment and economyperspective. Annals of Medicine and Surgery. 2020 Aug;56:38-42.

14. Bashir MF, Benjiang M, Shahzad L. A brief review of socio-economic and environmental impact of Covid-19. Air Quality, Atmosphere \& Health. 2020;13:1403-9.

15. Moreno C, Wykes T, Galderisi S, Nordentoft M, Crossley N, Jones N, et al. How mental health care should change as a consequence of the COVID-19 pandemic, The Lancet Psychiatry. 2020 Sep;7:813-24. 